\title{
Analysis of thermal models to determine the loss of life of mineral oil immersed transformers
}

\author{
Mohammad Tolou Askari ${ }^{1}$, Mohammad Javad Mohammadi ${ }^{2}$, Jagadeesh Pasupuleti ${ }^{3}$, Mehrdad \\ Tahmasebi $^{4}$, Shangari K Raveendran ${ }^{5}$, Mohd Zainal Abdin Ab Kadir ${ }^{6}$ \\ 1,2Department of Electrical Engineering, Semnan Branch, Islamic Azad University, Semnan, Iran \\ 3,5Institute of Sustainable Energy, Universiti Tenaga Nasional (UNITEN), Kajang, Malaysia \\ ${ }^{4}$ Department of Electrical Engineering, Ilam Branch, Islamic Azad University, Ilam, Iran \\ ${ }^{6}$ Institute of Power Engineering (IPE), Universiti Tenaga Nasional (UNITEN), Kajang, Malaysia \\ ${ }^{6}$ Centre for Electromagnetic and Lightning Protection Research (CELP), Faculty of Engineering, Universiti Putra \\ Malaysia, Serdang, Malaysia
}

\begin{tabular}{|c|c|}
\hline Article Info & ABSTRACT \\
\hline Article history: & Hot spot as well as top oil temperatures have played the most effective \\
\hline Received Dec 2, 2019 & $\begin{array}{l}\text { parameters on the life of the electrical transformers. The prognostication of } \\
\text { these factors is very vital for determining the residual life of the electrical }\end{array}$ \\
\hline Revised May 2, 2021 & transformers in the transmission and distribution systems. Thus, an accurate \\
\hline Accepted Jul 14, 2021 & $\begin{array}{l}\text { mathematical method is required to calculate the critical temperature such as } \\
\text { hot spot and top oil temperature based on the different types of thermal }\end{array}$ \\
\hline Keywords: & $\begin{array}{l}\text { models. In this study calculates the service life of the transformers based on } \\
\text { an accurate top oil temperature. Accordingly, An approach solution is given }\end{array}$ \\
\hline Electrical transformer & for calculating the thermal model. Also, findings are validated with true \\
\hline Hot spot temprature & $\begin{array}{l}\text { temperatures. Finally, this method is implemented on } 2500 \text { KVA electrical } \\
\text { transformer. }\end{array}$ \\
\hline Numerical analysis & \\
\hline
\end{tabular}

This is an open access article under the CC BY-SA license.

Thermal model

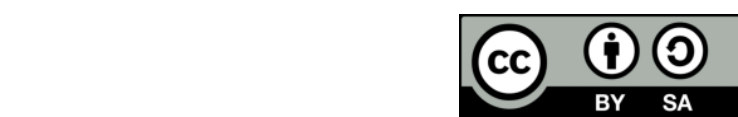

\section{Corresponding Author:}

Mohammad Tolou Askari

Department of Electrical Engineering, Semnan Branch

Islamic Azad University, Semnan, Iran

Email: m.askari@semnaniau.ac.ir

\section{INTRODUCTION}

Electrical transformers the facilities in electrical power networks that the correct operation of it has played main role in providing reliability of these systems. By noticing the costs of transformers and permanent connection of transformers to transmission and distribution systems, any action to increase the life cause improvement in the operation of power systems. Life of the electrical transformer and loading capabilities of this facilities depend on several parameters. Oil and paper in transformers are two insulation materials, that the integrity of them warranties the life of transformers. Hot spot temperature (HST) and top oil temperature (TOT) are two criteria to evaluate the integrity of these two insulation materials and transformers as important facility in power network [1]-[3]. These criteria determine the temperature limitation of transformer for loading capability, for example the IEEE standard suggests that the TOT rise over ambient temperature $65^{\circ} \mathrm{C}$ and depending on it has considered $110^{\circ} \mathrm{C}$ for HST [4]-[6]. It means that increasing the temperature of transformer over this standard value causes the degradation of insulation life of transformer. According to research, from $90^{\circ} \mathrm{C}$ to $110^{\circ} \mathrm{C}$, the aging rate of tensile strength approximately doubles every $5^{\circ} \mathrm{C}$ to $10^{\circ} \mathrm{C}$ temperature rise [2], [3], [7]-[9]. A. A. Taheri, A. Abdali and A. Rabiee [10] a thermal resistance with solar radiation is used to explain the heat transfer theory in transformer. The effect of 
long term ambient temperature was investigated in [11], [12]. There are some dynamic factors in oil immersed transformer such as ambient temperatures, winding losses and oil viscosity of transformer [3], [13]. In this article, two thermal models, classic thermal model as famous and reliable thermal model and dynamic thermal model as improved thermal model, has been used. Moreover, TOT and HST is calculated for both thermal model by IEEE standard method that has been available in [3] and also these temperatures are calculated by proposed method. To validate and show the tolerance of numerical technique, the results of models compared with measured value.

\section{LITERATURE REVIEW}

\subsection{Thermal model}

\subsubsection{Classic thermal model}

Thermal model is used to estimate the critical temperature of the transformer. The classic one was given base on the heat generated and distributed in the windings and oil of transformer [3], [9]. Figure 1 shows temperature distribution in the transformer.

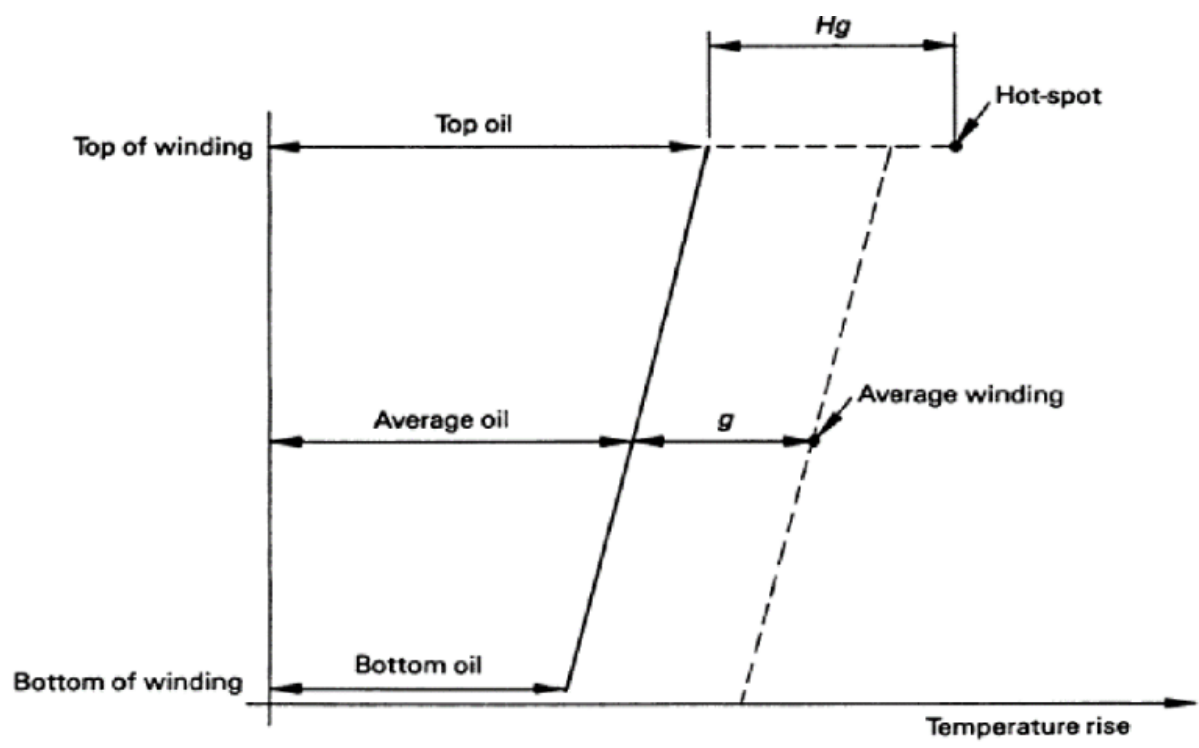

Figure 1. The temperature distribution in the transformer

The classic thermal model is used by a differential equation as [3]:

$$
T_{0} \frac{d \theta_{t o p}}{d t}=-\theta_{t o p}+\theta_{u}+\theta_{a m b}
$$

The solution as:

$$
\theta_{\text {top }}=\left(\theta_{u}+\theta_{a m b}-\theta_{\text {topi }}\right)\left(1-e^{-\left(\frac{t}{T_{0}}\right)}\right)+\theta_{\text {topi }}
$$

and

$$
\begin{aligned}
& \theta_{u}=\theta_{f l}\left[\frac{I_{p u}^{2} R+1}{R+1}\right]^{n} \\
& T_{0}=\frac{C \theta_{f l}}{P_{f l}}
\end{aligned}
$$

where: $\theta_{T O P}=$ Top-oil rise over ambient temperature $(\mathrm{C})$

$\theta_{u}=$ Ultimate top-oil rise for load L (C)

$\theta_{i}=$ Initial top-oil rise for $\mathrm{t}=0(\mathrm{C})$

$\theta_{f l}=$ Top-oil rise over ambient temperature at rated load

$T_{0}=$ Time constant

$n=$ Oil exponent 
$I=$ Specified load

$I_{\text {rated }}=$ Rated load

$I_{p u}=$ Ratio of specified load to rated load

The transient rise of the hottest spot of the winding higher than the upper limit of the oil temperature is determined by the following formula [3]:

$$
\Delta \theta_{H}=\left(\Delta \theta_{H, U}-\Delta \theta_{H, i}\right)\left[1-\exp ^{\frac{-t}{T_{0}}}\right]+\Delta \theta_{H, i}
$$

That the initial value for hot-spot temperature rise over top-oil temperature is given by:

$$
\Delta \theta_{H, i}=\Delta \theta_{H, R} I_{i, p u}^{2 m}
$$

The maximum hot spots are as follows:

$$
\Delta \theta_{H, U}=\Delta \theta_{H, R} I_{U, p u}^{2 m}
$$

The nominal hottest temperature spot value is given by:

$$
\Delta \theta_{H, R}=\Delta \theta_{H / A, R}-\Delta \theta_{T O, R}
$$

where: $\Delta \theta_{H}=$ Hottest temperature spot rise over top oil temperature (C)

$\Delta \theta_{H, U}=$ Maximum hottest temperature spot rise over maximum oil temperature for load $(\mathrm{C})$

$\Delta \theta_{H, i}=$ Initial hottest temperature spot rise over top oil temperature for $\mathrm{t}=0(\mathrm{C})$

$T_{0}=$ time constant of the transformer winding $(\mathrm{h})$

$t=$ Loading time (h)

$\Delta \theta_{H, R}=$ Nominal hot spot rising above maximum oil temperature (C)

$I=$ Current of load per unit

$\mathrm{M}=$ The exponent determines the non-linearity as shown in Table 1

The manufacturer has specified the amount of $\mathrm{n}$ for each mode of cooling. The amounts of $\mathrm{n}$ and $\mathrm{m}$ for each cooling method are shown in Table 1 [3].

Table 1. Exponents for temperature determination formulas

\begin{tabular}{ccc}
\hline cooling & $\mathrm{M}$ & $\mathrm{N}$ \\
\hline OA & 0.8 & 0.8 \\
FA & 0.8 & 0.9 \\
Non-directed FOA or FOW & 0.8 & 0.9 \\
Directed FOA or FOW & 1 & 1 \\
\hline
\end{tabular}

HST will be calculated by (9).

$$
\theta_{H S T}=\Delta \theta_{T O T}+\Delta \theta_{H S T}+\theta_{a m b}
$$

\subsubsection{Dynamic thermal model}

Firstly, A dynamic thermal model of electrical transformer has been offered by Swift based on the principals of heat transfer theory [14]-[17] after that an improved model has been introduced by Susa by assuming the non-linear thermal oil resistance base on swift's approach. In Susa's model the variations of viscosity with temperature were considered [9]. TOT of dynamic thermal model is governed by (1).

$$
\frac{1+R \times K^{2}}{1+R} \times \mu_{p u}^{n} \times \theta_{f l}=\mu_{p u}^{n} \times \tau_{0} \times \frac{d \theta_{o i l}}{d t}+\frac{\left(\theta_{o i l}-\theta_{a m b}\right)^{1+n}}{\theta_{f l}^{n}}
$$

Oil viscosity is added as a parameter. This can be determined by [18].

$$
\mu_{p u}=e^{\left[\left(\frac{2797.3}{\theta_{t o p}+273}\right)-\left(\frac{2797.3}{\theta_{f l}+273}\right)\right]}
$$

where: $K=$ load current per unit

$R=$ proportionality of load to no-load losses

$\tau_{0}=$ top oil time constant, (min)

$\theta_{f l}=$ rated top oil rise over ambient, $(\mathrm{K})$ 
$\theta_{\text {oil }}=$ top oil temperature gradient, $(\mathrm{K})$

$\theta_{a m b}=$ ambient temperature, $(\mathrm{K})$

$\mu_{p u}=$ oil viscosity per unit

$n=$ empirical constant, the amount of $\mathrm{n}$ has been specified for each cooling mode in Table 2 [2].

Tabel 2. Experimental value of $\mathrm{n}$

\begin{tabular}{cccc}
\hline Oil circulation & \multicolumn{3}{c}{$\mathrm{n}$} \\
\hline & \multicolumn{2}{c}{ With cooling } & without cooling \\
Initial oil circulation, Speed=0, (cold start) & ONAF/OFAF & ONAN & ONAN \\
Initial oil circulation, Speed $>0$, (transformer on load) & 0.5 & 0 & 0.25 \\
\hline
\end{tabular}

HST of dynamic thermal model is given as [19]:

$$
\left[K^{2} \times P_{w d, p u}\right] \times \mu_{p u}^{n} \times \Delta \theta_{h s, \text { rated }}=\mu_{p u}^{n} \times \tau_{w d, \text { rated }} \times \frac{d \theta_{h s}}{d t}+\left(\frac{\left(\theta_{h s}-\theta_{\text {oil }}\right)^{n+1}}{\Delta \theta_{h s, \text { rated }}^{n}}\right)
$$

Pwd,pu, is the load loss's dependence on temperature that can be determined by (13)

$$
P_{w d, p u}=P_{d c, p u} \times\left(\frac{\theta_{h s}+\theta_{k}}{\theta_{h s, r a t e d}+\theta_{k}}\right)+P_{e d d y, p u} \times\left(\frac{\theta_{h s, r a t e d}+\theta_{k}}{\theta_{h s}+\theta_{k}}\right)
$$

The behavior of the eddy losses and DC losses are shown in Peddy and Pdc respectively. DC loss is directly proportional to temperature, while eddy current loss is inversely proportional to temperature. $\Theta \mathrm{k}$ is the temperature coefficient of loss correction. Aluminum is equal to 225 and copper is equal to 235. Oil time constant $\left(\tau_{0}\right)$ is one of the most important parameters that should be determined accurately. Note that, there are specific methods for each thermal model to determine $\tau_{0}$. The oil time constant for dynamic thermal model is given by [20]: Note that, (14) is based on minute and (15) is per hours and depends on whether per hours or minutes have to be changed and for data which collected per hours it shouldn't multiply by 60 , it means that the oil time constant does not need to convert to minutes.

$$
\begin{aligned}
\tau_{0} & =\frac{C_{\text {th-oil }} \times \Delta \theta_{\text {oil }, \text { rated }}}{P_{\text {total }}} \times 60 \\
\tau_{0} & =\frac{C_{\text {th-oil }} \times \Delta \theta_{\text {oil }, \text { rated }}}{P_{\text {total }}}
\end{aligned}
$$

\section{RESEARCH METHOD}

\subsection{Solving techniques}

\subsubsection{IEEE standard method}

IEEE standards C57.91-1995 has offered an exponential method based on the (14) to calculate the TOT to determine the HST of transformers for classic thermal model [3]. In (14) is derived from (1) [21].

$$
\Delta \theta_{T O}=\left(\Delta \theta_{T O, U}-\Delta \theta_{T O, i}\right)\left[1-\exp ^{\frac{-1}{T_{0}}}\right]+\Delta \theta_{T O, i}
$$

The ultimate value of top oil acsent for each stage is calculated by,

$$
\Delta \theta_{T O, u}=\theta_{f l}\left[\frac{\left(I_{p u, u}^{2} R+1\right)}{(R+1)}\right]^{n}
$$

For calculating the initial value for the first time, $\mathrm{t}=0$, knowing the record of loading profile can be so useful. The current at $\mathrm{t}=0$, determined by RMS value of the loading currents for the former loadings [3]. Equation (3.5) can be used to estimate the initial value for other steps to calculate the top-oil temperature rise.

$$
\Delta \theta_{T O, i}=\theta_{f l}\left[\frac{\left(I_{p u, i}^{2} R+1\right)}{(R+1)}\right]^{n}
$$

\subsubsection{Numerical method}

Numerical methods are used to solve the ordinary differential equation. In this study, two types of numerical solvers are compared to determine the thermal-electrical models. The first model is related to 
Euler's method and is the simplest solver. Although this model is not an appropriate solver in most utilization, it reveals some common characteristics among different types of solvers. Runge-Kutta is the second type of solver, which is used in this paper. The fourth-order RungeKutta technique is the most widely used solution method. This solution technique, which begins with an initial value $\left(\mathrm{t}_{0}, \mathrm{y}_{0}\right)$, has four slopes,

$$
\begin{aligned}
& K_{1}=f\left(t_{0}, y_{0}\right), K_{2}=f\left(t_{0}+\frac{h}{2}, y_{0}+\frac{h}{2} K_{1}\right), \\
& K_{3}=f\left(t_{0}+\frac{h}{2}, y_{0}+\frac{h}{2} K_{2}\right), K_{4}=f\left(t_{0}+h, y_{0}+h K_{3}\right)
\end{aligned}
$$

With these slopes, the next value of the dependent variable can be determined as,

$$
y_{k}=y_{k-1}+h \frac{K_{1}+2 K_{2}+2 K_{3}+K_{4}}{6}
$$

TOT and HST of transformer can be computed for dynamic thermal model according to the algorithm has been given in Figure 2. The input data can be classified in two groups, constant and variable input data. Constant data are n, m, weight of the oil per kg, load losses and no-load losses, oil time constant and winding time constant, DC and eddy losses, And the hot spot temperature under rated load. While variable input data that can be changed by time include current or loading of transformers and ambient temperature.

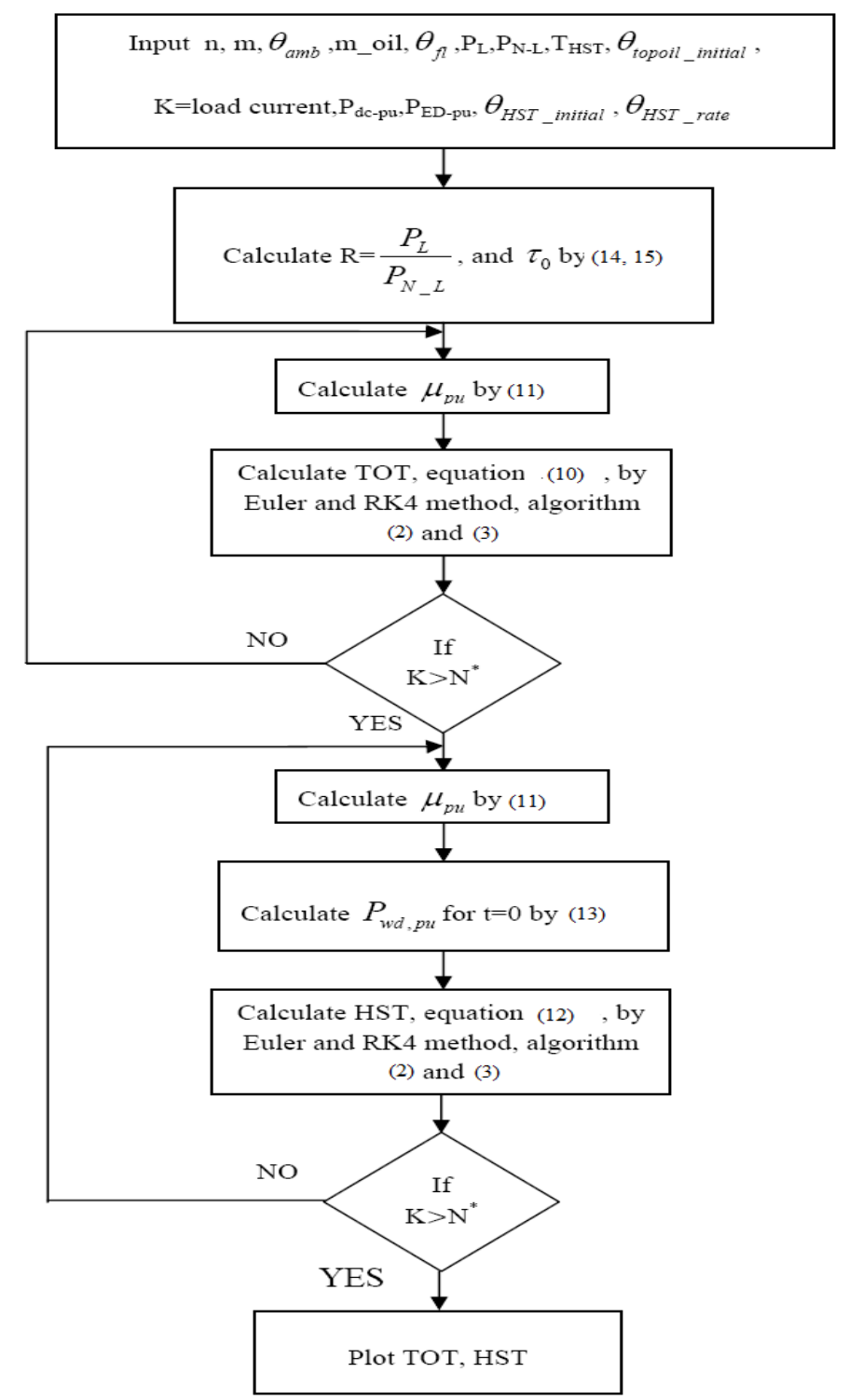

Figure 2. HST and TOT for dynamic thermal model *: $\mathrm{N}$ is total number of load current that are collected 


\subsection{The loss of life of the transformer}

The quality of paper and oil which are applied in electrical transformer is directly proportional to the efficiency of it. However, the deterioration of paper can determine the loss of life (LOL) the mineral oil immersed transformers. Heat, oxygen and moisture are the most important factors to deteriorate the paper of electrical transformers. Insulation degradation can be simulated as a quantity per unit and calculated as [4], [22];

$$
\text { per }- \text { unit }- \text { life }=A e^{\left[\frac{B}{\theta_{H S T}+273}\right]}
$$

where: $\mathrm{A}=\mathrm{is}$ an adjusted constant based on the temperature determined for a per unit life,

$\mathrm{B}=\mathrm{is}$ the slope rate of aging.

IEEE standard C57.91-1995 considered $\mathrm{B}=15000$ is appropriate and is used in per-unit-life equation for loading of transformers. For $\theta_{H S T}=110 \mathrm{C}$, and per-unit-life $=1$, the value of $\mathrm{A}$ constant becomes $9.8 \times 10-18$. The aging factor can be calculated [3], [23]

$$
F_{A A}=e^{\left[\frac{15000}{383}-\frac{15000}{\theta_{H}+273}\right]}
$$

The equivalent aging of the electrical transformer based on reference temperature for hottest spot is $110^{\circ} \mathrm{C}$ could be calculated as [3], [24], [25]:

$$
F_{E Q A}=\frac{\sum_{n=1}^{N} F A A_{n} \Delta t_{n}}{\sum_{n=1}^{N} \Delta t_{n}}
$$

where: $\mathrm{F}_{\mathrm{EQA}}=$ aging factor

$\mathrm{n}=$ time interval index

$\mathrm{N}=$ total time duration

$\Delta t_{n}=$ time interval

And, the percentage of LOL can be determined as [26], [27]:

$$
\% \text { loss }- \text { of }- \text { life }=\frac{F_{E Q A} \times t \times 100}{N I L}
$$

\subsection{Emprical tests for case of study}

\subsubsection{Three phase 2500 KVA transformer}

The ratio of voltage of $2500 \mathrm{KVA}$ transformer is $20 / 0.4 \mathrm{KV}$, and without external cooling, ONAN. Three different loading currents are considered in this paper that are shown in Table 3. For this transformer the low voltage and high voltage windings have one and two axial cooling duct respectively. The transformer equipped by 17 thermocouples located as follows: One is mounted $50 \mathrm{~mm}$ under the tank cover of electrical transformer, 2 sensors in the oil enclosure, 4 sensors is located on the bottom of outside surface of the tank, 2 in the bottom of the tank, 4 in duct outlet in top and bottom, 4 in duct inlet in top and bottom.

Table 3. Load levels for transformer

\begin{tabular}{cc}
\hline Time intervals (minutes) & Load (PU) \\
\hline $0-300$ & 1 \\
$300-382$ & 2 \\
$382-415$ & 0 \\
\hline
\end{tabular}

\subsubsection{Three phase 30 MVA transformer}

The voltage ratio of this transformer is $33 / 11 \mathrm{KV}$. Also, cooling system is oil natural and air force (ONAF). 3 thermometers are used to indicate the winding and top oil temperatures for high and low voltage windings. Also, they are used for collecting ambient temperature. This data is necessary to verify the suggested techniques provided in this article. The output of the thermometer is a function of the 4 to $20 \mathrm{~mA}$ current that must be converted to temperature (C).

\section{RESULTS AND DISCUSSION}

HST of each transformer has been plotted for both distribution transformers. LOL of transformers for each thermal model has been compared with measured value and were indicated in Tables 4 and 7 for 
classic thermal model and Tables 5 and 8 for dynamic thermal model. Finally, Tables 6 , and 9 tabulate the error of numerical methods rather than exponential method. By comparing the error of each thermal model for $2500 \mathrm{KVA}$ transformer, which is demonstrated in Tables 4 and 5, the less error of dynamic thermal model rather than classic thermal model is comprehensible. These errors for numerical methods are less than exponential method.

\subsection{KVA transformer}

$2500 \mathrm{KVA}$ transformer was tested for 415 minutes. Figure 3 shows the comparison between the measured HST and HST achieved by the numerical methods and exponential method. Graphs have been plotted based on the classic model. Figure 4 shows the comparison of the hot spot temperature of a 2500 KVA transformer with the hot spot temperature calculated using two numerical methods (RungeKutta and Euler methods).This graph has been plotted based on the dynamic thermal model.

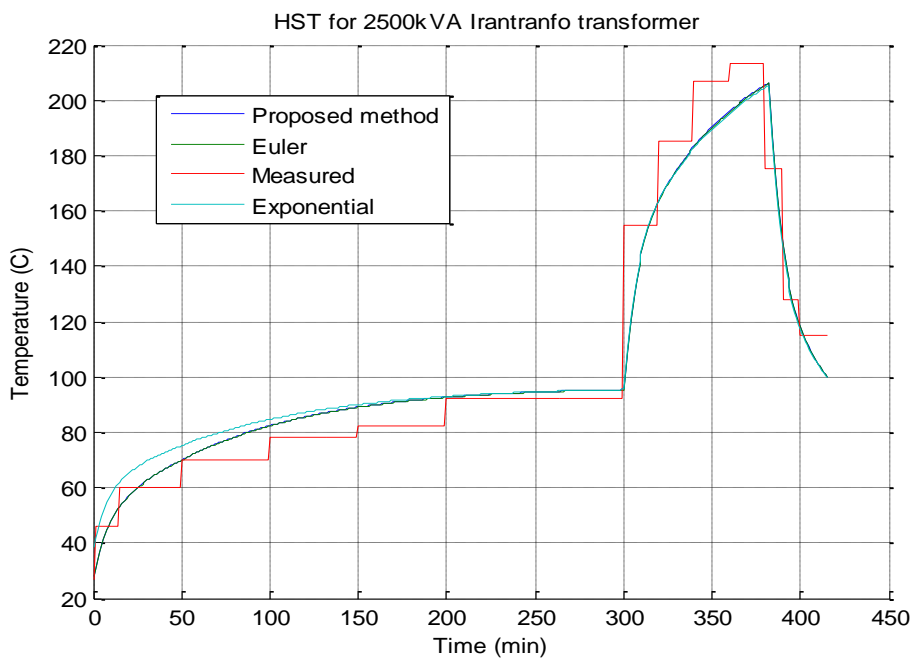

Figure 3. Hot spot temperature of 2500 KVA transformer: Classic thermal model

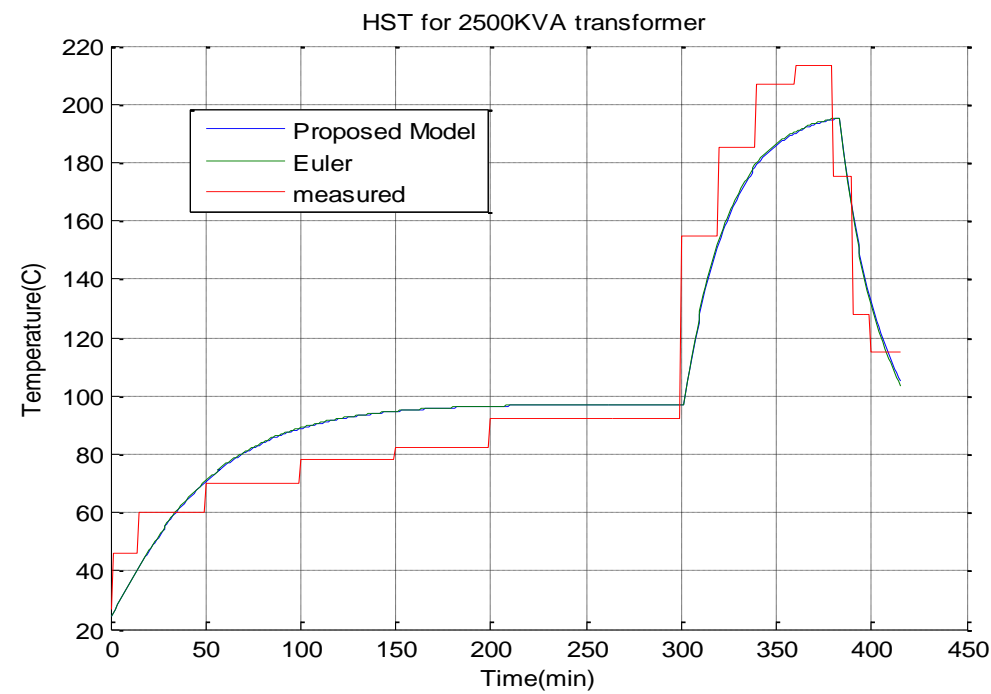

Figure 4. Hot spot temperature of 2500 KVA transformer: Dynamic thermal model

In Tables 4 and 5 show the comparison between the errors achieved for classis and dynamic thermal models respectively. These errors given the differences between the numerical methods and exponential methods with measured. In addition, the loss of life of the $2500 \mathrm{KVA}$ transformer is compared with measured 
value in the Table 6 for two types of the thermal models. Thermal models have been calculated based on R-K technique. This comparison shows that the accuracy of the dynamic thermal model is higher than that of the classical thermal model.

Table 4. Classic thermal model of $2500 \mathrm{KVA}$ transformer (ERROR OF LOL)

\begin{tabular}{cc}
\hline Error for RK4 $\mid($ LOLNUM - LOLMeasured $) \mid$ & Error of exponential|(LOLIEEE - LOLMeasured $) \mid$ \\
\hline 1.7052 & 2.7643 \\
\hline
\end{tabular}

Table 5. Dynamic thermal model of 2500 KVA transformer (ERROR OF LOL)

\begin{tabular}{cc}
\hline Error for RK4 method |(lolRK4 - lolMeasured $) \mid$ & Error for Euler method $\mid($ lolEuler - lolMeasured $) \mid$ \\
\hline 0.7806 & 1.4912
\end{tabular}

Table 6. Error of thermal models: Different solving technique

\begin{tabular}{ccc}
\hline $\begin{array}{c}\text { numerical technique } \\
\text { (Dynamic thermal model ) }\end{array}$ & $\begin{array}{c}\text { numerical technique } \\
\text { (Classic thermal model) }\end{array}$ & $\begin{array}{c}\text { exponential technique } \\
\text { (Classic thermal model) }\end{array}$ \\
\hline 0.2358 & 2.2503 & 2.7643 \\
\hline
\end{tabular}

\section{CONCLUSION}

Several thermal models and solution are suggested for solving various thermal models to calculate the TOT and HST of transformer due to loss of life evaluation. These methods involved are linear and nonlinear regression and exponential methods that are proposed by IEEE standard. Numerical methods can be used as solution to calculate the thermal model, $\mathrm{R}-\mathrm{K}$ technique is an improved numerical method proposed in this research for solving two types of thermal models the first one is classical thermal model that was suggested by IEEE standard C57.91-1995 and the second one is thermal-electrical model or dynamic thermal model that assumed number of variable parameters such as viscosity of oil, ambient temperature, eddy losses. According to the results the proposed technique for solving the thermal models shows improved accuracy over the traditional methods.

\section{ACKNOWLEDGEMENTS}

The authors of this paper would like to appreciate Universiti Tenaga Nasional (UNITEN), Malaysia, for funding this publication through BOLD 2025 research grant (RJO10517844/071).

\section{REFERENCES}

[1] M. Djamali and S. Tenbohlen, "Hundred years of experience in the dynamic thermal modelling of power transformers," IET Generation, Transmission \& Distribution, vol. 11, pp. 2731-2739, 2017.

[2] H. Nafisi, "Investigation on distribution transformer loss-of-life due to plug-in hybrid electric vehicles charging," International Journal of Ambient Energy, vol. 42, pp. 744-750, 2021, doi: 10.1080/01430750.2018.1563816.

[3] IEEE, "'Guide for Loading Mineral-Oil-Immersed Power Transformers" C57.91-1995.," ed, 1995.

[4] C.-c. Sun, C. Xiao, J. Hou, L. Kong, J. Ye, and W.-j. Yu, "Analysis of Factors Affecting Temperature Rise of Oilimmersed Power Transformer," in Journal of Physics: Conference Series, 2020, p. 012087, doi:10.1088/17426596/1639/1/012087.

[5] J. I. Aizpurua, S. D. J. McArthur, B. G. Stewart, B. Lambert, J. G. Cross and V. M. Catterson, "Adaptive Power Transformer Lifetime Predictions Through Machine Learning and Uncertainty Modeling in Nuclear Power Plants," in IEEE Transactions on Industrial Electronics, vol. 66, no. 6, pp. 4726-4737, June 2019, doi: 10.1109/TIE.2018.2860532.

[6] V. Bissuel et al., "Novel Approach to the Extraction of Delphi-like Boundary-Condition-Independent Compact Thermal Models of Planar Transformer Devices," 2018 24rd International Workshop on Thermal Investigations of ICs and Systems (THERMINIC), 2018, pp. 1-7, doi: 10.1109/THERMINIC.2018.8593283.

[7] B. C. Lesieutre, W. H. Hagman and J. L. Kirtley, "An improved transformer top oil temperature model for use in an on-line monitoring and diagnostic system," in IEEE Transactions on Power Delivery, vol. 12, no. 1, pp. 249-256, Jan. 1997, doi: 10.1109/61.568247.

[8] L. W. Pierce, "Predicting liquid filled transformer loading capability," [1992] Record of Conference Papers Industry Applications Society 39th Annual Petroleum and Chemical Industry Conference, 1992, pp. 197-207, doi: 10.1109/PCICON.1992.229310. 
[9] L. Wang, X. Zhang, R. Villarroel, Q. Liu, Z. Wang, and L. Zhou, "Top-oil temperature modelling by calibrating oil time constant for an oil natural air natural distribution transformer," IET Generation, Transmission \& Distribution, vol. 14, pp. 4452-4458, 2020, doi: 0.1049/iet-gtd.2020.0155.

[10] A. A. Taheri, A. Abdali and A. Rabiee, "A Novel Model for Thermal Behavior Prediction of Oil-Immersed Distribution Transformers With Consideration of Solar Radiation," in IEEE Transactions on Power Delivery, vol. 34, no. 4, pp. 1634-1646, Aug. 2019, doi: 10.1109/TPWRD.2019.2916664.

[11] M. M. M. Salama, D. A. Mansour, S. M. Abdelmaksoud and A. A. Abbas, "Impact of Long-Term Climatic Conditions on the Ageing and Cost Effectiveness of the Oil-Filled Transformer," 2018 Twentieth International Middle East Power Systems Conference (MEPCON), 2018, pp. 494-499, doi: 10.1109/MEPCON.2018.8635184.

[12] A. Santisteban, A. Piquero, F. Ortiz, F. Delgado, and A. Ortiz, "Thermal modelling of a power transformer disc type winding immersed in mineral and ester-based oils using network models and CFD," IEEE Access, vol. 7, pp. 174651-174661, 2019.

[13] M. M. Salama, D.-E. A. Mansour, M. Daghrah, S. M. Abdelkasoud, and A. A. Abbas, "Thermal performance of transformers filled with environmentally friendly oils under various loading conditions," International Journal of Electrical Power \& Energy Systems, vol. 118, p. 105743, 2020, doi: 10.1016/j.ijepes.2019.105743.

[14] G. Swift, T. S. Molinski and W. Lehn, "A fundamental approach to transformer thermal modeling. I. Theory and equivalent circuit," in IEEE Transactions on Power Delivery, vol. 16, no. 2, pp. 171-175, April 2001, doi: $10.1109 / 61.915478$

[15] M. S. Mahdi, et al., "Effect of fin geometry on natural convection heat transfer in electrical distribution transformer: Numerical study and experimental validation," Thermal Science and Engineering Progress, vol. 14, p. 100414, December 2019, doi: 0.1016/j.tsep.2019.100414.

[16] M. Aslam et al., "Dynamic Thermal Model for Power Transformers," in IEEE Access, vol. 9, pp. 71461-71469, 2021, doi: 10.1109/ACCESS.2021.3078759.

[17] I. Daminov, R. Rigo-Mariani, R. Caire, A. Prokhorov, and M.-C. Alvarez-Hérault, "Demand Response Coupled with Dynamic Thermal Rating for Increased Transformer Reserve and Lifetime," Energies, vol. 14, no. 5, 2021, doi: 10.3390/en14051378.

[18] L. Jauregui-Rivera and D. J. Tylavsky, "Acceptability of Four Transformer Top-Oil Thermal Models-Part I: Defining Metrics," in IEEE Transactions on Power Delivery, vol. 23, no. 2, pp. 860-865, April 2008, doi: 10.1109/TPWRD.2007.905555.

[19] C. Gezegin, O. Ozgonenel and H. Dirik, "A Monitoring Method for Average Winding and Hot-Spot Temperatures of Single-Phase, Oil-Immersed Transformers," in IEEE Transactions on Power Delivery, doi: 10.1109/TPWRD.2020.3035842.

[20] D. Susa, J. Palola, M. Lehtonen and M. Hyvarinen, "Temperature rises in an OFAF transformer at OFAN cooling mode in service," in IEEE Transactions on Power Delivery, vol. 20, no. 4, pp. 2517-2525, Oct. 2005, doi: 10.1109/TPWRD.2005.852284.

[21] L. Wang et al., "Improved Dynamic Thermal Model With Pre-Physical Modeling for Transformers in ONAN Cooling Mode," in IEEE Transactions on Power Delivery, vol. 34, no. 4, pp. 1442-1450, Aug. 2019, doi: 10.1109/TPWRD.2019.2903939.

[22] P. Trnka, J. Hornak, P. Prosr, O. Michal and F. Wang, "Various Aging Processes in a Paper-Natural Ester Insulation System in the Presence of Copper and Moisture," in IEEE Access, vol. 8, pp. 61989-61998, 2020, doi: 10.1109/ACCESS.2020.2983907.

[23] M. Mikhak- Beyranvand, J. Faiz, and B. Rezaeealam, "Thermal analysis and derating of a power transformer with harmonic loads," IET Generation, Transmission \& Distribution, vol. 14, pp. 1233-1241, 2020, doi: 0.1049/ietgtd.2019.0703.

[24] A. Elmoudi, M. Lehtonen and H. Nordman, "Effect of harmonics on transformers loss of life," Conference Record of the 2006 IEEE International Symposium on Electrical Insulation, 2006, pp. 408-411, doi: 10.1109/ELINSL.2006.1665344

[25] R. Diao, Z. Hu, Y. Long, X. Hu and X. Duan, "Two-stage Electric Vehicle Charging Strategy for Reducing both Charging Cost and Transformer Aging," 2020 IEEE Sustainable Power and Energy Conference (iSPEC), 2020, pp. 2187-2192, doi: 10.1109/iSPEC50848.2020.9351067.

[26] L. R. Chandran, G. A. Babu, M. G. Nair, and K. Ilango, "A review on status monitoring techniques of transformer and a case study on loss of life calculation of distribution transformers," Materials Today: Proceedings, 2020, doi: 10.1016/j.matpr.2020.10.290.

[27] V. Mehta and J. Vajpai, "Analysis of Hotspot Development in Power Transformer and Its Life Estimation," in Intelligent Energy Management Technologies, ed: Springer, 2021, pp. 319-334, doi: 10.1007/978-981-15-88204_30. 


\section{BIOGRAPHIES OF AUTHORS}
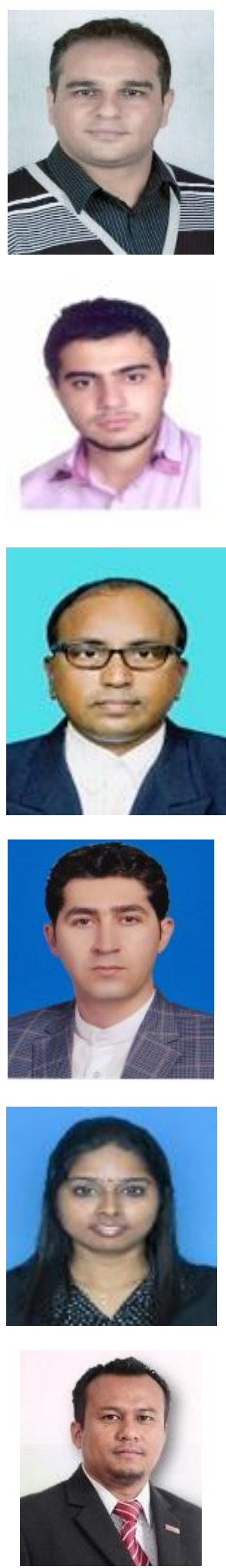

Mohammad Tolou Askari received his Bachelor degree in Power Electrical Engineering from University of Applied Science and Technology of Mashhad in 2005, and the Master degree in Power Electrical Engineering in 2008. He received Ph.D. degree in Power Electrical Engineering from University Putra Malaysia in 2004. Currently, he is a senior lecturer in the Department of Electrical and Electronics Engineering, Faculty of Engineering, Islamic Azad University

Mohammadi M. Javad received the B.Eng degree in Electrical in 2018 and master of power system engineering from Islamic Azad university of Semnan.his research interests include comparison thermal model and numerical solution methods estimate Insulation life of electrical transformers power system engineering from Islamic Azad university of Semnan.

Dr. Jagadeesh Pasupuleti is the Head of Hybrid Renewable Energy Systems, Institute of Sustainable Energy, Universiti Tenaga Nasional, Malaysia. He is a Senior Member of IEEE (USA), Member of IET (UK), Chartered Engineer (UK), Professional Review Interviewer for CEng (UK), Member of EI (UK), Member of BEM (Malaysia) and Member of ISTE (India). He has supervised 30 postgraduate students, published over 100 papers and involved in 50 research and consultancy projects funded around $\$ 3$ million in renewable energy.

Mehrdad Tahmasebi received his Bachelor degree in Power Electrical Engineering from Islamic Azad University, South Tehran branch, Iran in 2002, and the Master degree in Power Electrical Engineering\&Electrical Energy Management from Amirkabir University of Technology, Tehran, Iran in 2010. He received Ph.D. degree in Power Electrical Engineering from The National Energy University of Malaysia in 2015. Currently, he is an Assistant Professor in the Department of Electrical Engineering, Islamic Azad University (Ilam Branch).

Shangari K. Raveendran received the B. Eng degree in Electrical and Electronic in 2009 and Masters in Electrical Engineering in 2011 Engineering from Universiti Tenaga Nasional. Currently, she is a lecturer in the Department of Electrical and Electronics Engineering, College of Engineering, Universiti Tenaga Nasional. Her research interests includes power system, renewable energy, virtual power plant, energy management system and battery storage system.

Mohd. Zainal Abidin Ab. Kadir received the B. Eng degree in Electrical and Electronic Engineering from Universiti Putra Malaysia in 2000 and Ph.D. degree in High Voltage Engineering from The Universiti of Manchester in UK in 2006. Currently, he is a professor in the Department of Electrical and Electronics Engineering, Faculty of Engineering, University Putra Malaysia. 